\title{
Status Quo and Countermeasures on Physical Education in Rural Primary and Middle Schools
}

\author{
Guoquan Zhang ${ }^{1, a}$, Zhenxing Zhang ${ }^{2, b}$ \\ ${ }^{1}$ Department of Physical Education, Bohai University, Jinzhou, 121013, China \\ ${ }^{2}$ School of Mathematics and Physics, Bohai University, Jinzhou, 121013, China \\ a673722120@qq.com, bhenxingzhang2016@163.com
}

Keywords: rural primary and middle schools; physical education; status quo; countermeasures

\begin{abstract}
China's urban and rural dual structure makes education development unbalanced, obvious difference between urban and rural areas, rural school sports education lags behind, rural primary and middle schools physical education gets out of the trouble as soon as possible is the problem to be solved. This paper takes the basic theory as guidance, in view of the current situation of rural primary and middle schools physical education, which puts forward some countermeasures to strengthening rural primary and middle schools physical education: straightening out the relationship between physical education and quality education promotes students all-round development and healthy growth; strengthen the concept of physical and health teaching, the whole society forms a joint force to promote the development of school sports; strengthen the management of schools sports work and fully update teaching concepts of physical education; strengthen the sports teachers team construction, improve the business quality and ability of sports teachers in many ways; set up special physical education funds to gradually solve the problems of shortage of venues, equipments and facilities; strengthen the construction of evaluation mechanism to ensure that physical jobs make benign operations in the orbit of quality education; vigorously promote the comprehensive reform of education in urban and rural areas, and encourage urban and rural sports teachers to exchange and cooperate; promote the implementation of sunshine sports activities and carry out a rich and colorful extracurricular sports.
\end{abstract}

\section{Introduction}

Physical education is an integral part of education. It is a purposeful, planned and organized education process through physical activities and other ancillary measures. Physical education itself is a complete system, divided into two categories: general physical education and specialized physical education. The basic characteristic is outstanding education and teaching. Physical education takes the teaching as the main approach, the classroom instruction or the specialized guidance as the main form, and physical exercises and health care as the main means.

Physical education is an important part of basic education, at the same time, over the years which has made considerable progress, there are also many problems which are not adapted to the development of the times, it is a weak link of rural primary and middle schools basic education which has not been changed and still has a certain distance to the requirements of quality education, it is difficult to keep up with the pace of social economic and educational development in twenty-first century. Therefore, today that sports education faces the opportunities and severe challenges, how to strengthen the self construction of physical education in rural primary and middle schools and promote the development of aesthetic education has become an important and urgent task for physical education workers. 


\section{Research Significance}

Education services the society, social and economic development affect the pace of education forward, therefore, the study of physical education cannot be divorced from social life. Physical education is an important part of education, which plays an irreplaceable role in the all-round and harmonious development of students. As an important course of basic education stages, physical education teaching has been running through students' study and life. The education management department also attaches great importance to the development of basic physical education in rural primary and middle schools, and emphasizes the implementation of quality education for primary and middle schools students. Pay attention and strengthen the rural school education, which will improve the overall level of basic education to a certain extent, developing the physical education in rural schools will be conducive to further play the function of schools sports, promote the healthy growth of young students, improve the health level of the next generation and the quality of the whole nation, but also conducive to improve and promote the development of rural sports.

Strengthen the propaganda of the status, function and significance of rural school sports, improve the understanding level of persons of every condition on rural school sports. Give full play to the organization, supervision and help of the administrative department for education for rural schools sports. Guide the broad masses of people to support the development of rural school physical education, governments at all levels should attach great importance to the status and significance of rural school sports in the national fitness strategy. This article makes investigation on the part of rural primary and middle schools physical education, summing up the pros and cons according to the present situation of education, aiming at the existing problems of rural primary and middle schools physical education, putting forward targeted solutions provides a reference for further reform and deepening development of basic physical education, also indicates the direction for the scientific development of rural primary and middle schools physical education. According to the actual situation, study the content of physical education, the effectiveness of education, teachers, educational facilities and teaching concepts to put forward reasonable reform measures, which has practice value and plays a positive role in promoting the development of basic physical education in rural primary and middle schools.

\section{Status Analysis}

As an important component of national education, school physical education is the basis of the national sports. Rural education is the main part of China's basic education, which is the basis for developing rural talents resource and improving the quality of rural workers. Rural primary and middle school physical education is also an important part of school education, directly related to the overall quality of the new generation. Rural primary and middle schools in China account for eighty-nine percent of the total number of primary and middle schools, the number of rural students accounts for seventy-four percent of the total number of students. Rural school physical education is the main component of school sports, and the quality of rural physical education will directly affect the quality of school physical education and school education in our country.

With the reform and development of basic education, especially the advancing quality education, basic physical education has made obvious achievements, educational administrative departments at various levels have initially established the management, consultation, teaching and research institutions of physical education in primary and middle schools, which has changed the condition that no special institutions and personnel manage physical education in the past; a series of laws and regulations which guide the teaching work of physical education in primary and middle schools have been formulated to change the lax situation that no law can be followed for physical education, the rate of physical education curriculum in primary and middle schools has risen steadily which changed the situation that physical education has a large white area for a long time; the introduction of a variety of foreign famous sports teaching methods, the teaching level has been significantly improved; carrying out a series of rich and colorful extracurricular sports activities effectively 
promotes the development of school physical education. It can be said that it is the best development period in the history of physical education in our country. However, from a nationwide perspective, the development of physical education is still very unbalanced. Physical education teachers formation and teaching equipment configuration in large and medium cities, and developed areas are basically equipped. The primary and middle schools in these areas can basically carry out physical education according to the requirements of the curriculum standards. But in the underdeveloped areas, especially in the vast rural areas, physical education teachers are seriously inadequate, teaching equipment investment is not enough, there is no fundamental guarantee for physical education, this situation has severely restricted the popularity of basic physical education in our country, objectively, the ethical bottom line of educational equity is trampled, this is contrary to the spirit of quality education, which is being pushed forward at present in our country.

Most researchers in our countries study the physical education in rural primary and middle schools from several aspects, such as sports facilities, physical education teachers, physical education situation and teaching funds, which provides basic data for understanding rural primary and middle school physical education status in a certain extent. However, some research contents are too little or not involved, such as the extracurricular sports activities and training, sports competition, development and utilization of sports school-based curriculum resources, professional development and occupation morality of physical teachers, school sports supervision and evaluation mechanism, school sports management system, in addition, research emphases are not prominent enough such as the education attitude of school and education leadership at all levels, the educational philosophy of all walks of life, sports teaching routines. Some research methods are not rich enough, questionnaires, interviews and literature collected data are too small to be convincing, and there is insufficient data to support for the argument. The subjects were narrow, mainly in the school, and rarely extended out of school.

\section{Puts Forward Countermeasures}

Aiming at the existing problems of rural primary and middle school physical education, applying the physical education basic theory, combining with national policies and regulations, and drawing on the experience of typical developed countries, countermeasures put forward by this paper for strengthening rural primary and middle school physical education are as follows:

First, straighten out the relationship between physical education and quality education, promote the all-round development and healthy growth of students. Quality education is the actual needs of human and social development, comprehensively improving the basic quality of all students as the fundamental purpose, which respects students' subject and subjective initiative, focuses on the development of students' wisdom potential and the education that forms students' sound personality as the fundamental characteristics. Physical education, the same as moral education, intellectual education and aesthetic education, which are all important parts of cultivating students' all-round development, and also important links to improve the overall quality of students. Only deeply understanding the connotation of quality education and health education, rationalizing the relationship between physical education, quality education and health education forms a linkage mechanism, which can promote students' healthy growth and all-round development.

Second, strengthen the concept of sports and health teaching, the whole society forms a joint force to promote the development of schools' physical education. Physical and health education should be aimed at promoting students' physical and mental health, combining "moral, intellectual, physical, aesthetic and labor" promotes the all-round development of students' physical and mental health. First, strengthen students' physical training, so that students learn to apply sports skills on the basis of mastering sports and health; second, cultivate students' interest in sports, so that students love sports; third, help students develop a correct attitude; fourth, improve students' own sense of responsibility, develop a positive and optimistic lifestyle; fifth, fully carry forward the sports spirit in the physical education, so that students enhance interpersonal communication ability and team cooperation consciousness in daily life. 
Third, strengthen the management of school physical education, comprehensively update the teaching concept of physical education. In accordance with the requirements of the times, update the teaching concept of physical education, give full play to the importance of physical education teaching to students' growth. Teachers need to deeply understand the nature of the course and grasp the sports curriculum standard, actively interact with students in the teaching process, deal with the relationship between imparting knowledge and cultivating ability, pay attention to training students' independence and autonomy, arouse students' enthusiasm and make every student develop fully. School leaders should attach great importance to continuously improving the software and hardware environment of physical education; strengthen physical education activities, standardize the teaching of physical education classroom, which promotes the teaching of physical education; popularization and improvement are combined to carry out various sports activities extensively.

Fourth, strengthen the construction of physical education teachers, improve the professional quality of physical education teachers through many channels. The construction of teaching staff is a long-term and complex project, which is the key to comprehensively improve the quality of education teaching and the core competitiveness of schools. Physical education teachers should change ideas, enrich knowledge and expand knowledge hierarchy. Schools should increase investment in school sports and build teaching platforms for teachers. The government and relevant departments should introduce special policies to promote the status of physical education teachers. Strengthen the training work of the physical education teaching staff, train sports talents in rural schools, grasp the continuing education of physical education teachers, avoid the formalization of continuing education. Adopting multi-level, multi-channel and multiform, mainly amateur and short-term training, which strengthens the scientific research consciousness.

Fifth, set up special physical education funds to gradually solve the shortage of venues, equipments and facilities. Physical venues, equipments and facilities are necessary conditions to ensure the normal development of physical education, extracurricular physical activities and training. Attach importance to the status of school sports and increase the input of special sports funds. The sports funds should account for a certain proportion in education funding, multi-channel and multi-channel collecting of rural schools physical funds, which creates conditions for increasing physical funds, and makes schools physical venues, equipments and facilities gradually updated and supplied. At the same time, reasonably using and developing sports resources, playing a variety of functions of sports equipments, which makes limited sports equipments to achieve maximum training effect. Advocate self-made simple equipments, cultivate students' hands-on and creative ability, enrich the content of physical education.

Sixth, strengthen the construction of evaluation mechanism to ensure the healthy operation of physical education in the track of quality education. Teaching evaluation makes judgments on the teaching process and results based on teaching objectives, which is the activity servicing for teaching decision-making and the process which makes judgments for the realistic or potential value of teaching activities. The content of evaluation mainly includes the organization management, education teaching, conditions guarantee, students' physique and supervision inspection in school physical education. The administrative departments of education should strengthen the evaluation management of schools physical education work, set up evaluation expert consultation organizations, establish physical work quality monitoring information systems. The assessment work should be comprehensive, accurate and objective to ensure the rigorous and orderly assessment process, and ensure fair and equitable evaluation results, which timely improves schools sports work.

Seventh, actively promote the comprehensive reform of urban and rural education, encourage exchanges and cooperation between urban and rural physical teachers. The educational concept and management level are the key links to promote the comprehensive reform of urban and rural education. Integrating the advanced educational concepts and management experience of urban schools into rural schools, which achieves the double standard of soft environment and hard environment of rural education, and realizes that high quality management resources are shared in urban and rural schools. Urban and rural schools physical education faculty are relatively large,, the 
education department should carry out extensive exchanges and cooperation between different schools, attract urban sports teachers or sports professionals to direct work in the rural areas, dispatch rural sports teachers to urban schools to learn experience to improve the teaching ability. Promote exchanges and cooperation with higher physical education institutions, which specially services for rural schools.

Eighth, promote the implementation of sunshine physical activities, carry out rich and colorful extracurricular sports. Carrying out "sunshine Sports" in primary and middle schools is of great significance to enrich students' spare time life, actively promote the goal of exercising sunshine for an hour every day and comprehensively promote the improvement of students' physical quality. The development of extracurricular sports activities is beneficial to train students' interest and hobbies in sports, cultivate students' group consciousness and interpersonal skills, and promote the all-round development of students' personality. While doing well in efficient classroom teaching, extracurricular sports activities should be carried out conscientiously, cultivating students' good interests and hobbies, developing students' personality and enriching the campus cultural life, which promotes the smooth development of various of school work.

\section{Conclusion}

Physical education is an important part of basic education, which shoulders the historical task of improving the physical quality of students, promoting the physical and mental health of young people, and cultivating all-round development of qualified personnel in twenty-first century, related to many aspects of the quality of national health and the improvement of the comprehensive national strength. Primary and middle school is an important stage to promote the healthy growth of young people and develop good fitness habits. Good physical education, on the one hand, which can cultivate the sports interest of primary and middle school students, form good fitness habits to lay a good foundation for lifelong sports; on the other hand, it is of great significance to train reserve talents of competitive sports. The study of this paper takes the basic theory as guidance, on the basis of the analysis of the present situation of physical education in rural primary and middle schools, pointing out the existing problems, which puts forward some countermeasures for strengthening rural primary and middle schools physical education to fundamentally solve various problems of physical education in rural primary and middle schools, improve the physical education effect. The purpose of this paper is to research and explore new theories and new methods which promote rural primary and middle schools physical education reform to solve key problems influence on basic physical education in rural primary and middle schools, which provides a theoretical basis for the educational administration department, rural primary and middle schools make the physical education planning, improve the construction of the physical education curriculum system, which promotes the overall improvement of the physical quality of rural primary and middle school students. In theory, they make further efforts to enrich and supplement the existing theories and methods of basic education. In practice, they can provide a certain scientific reference for the decision-making behavior of schools or education departments.

\section{References}

[1] FU Dong, XIAO Jin-yong, Status Quo and Development Strategies of PE Teachers in Rural Primary and Secondary Schools in Sichuan Province," Journal of Wuhan Institute of Physical Education, vol. 48, no. 9, pp. 90-93, 2014.

[2] SHI Lei. "Dialectical relation between physical education and quality education and health education," New West, vol. 14, no. 24, pp. 104+106, 2013.

[3] SONG Hui-ying, "Strengthen the function and measure of physical education and health education," Western China Quality Education, vol. 3, no. 1, pp. 171-171, 2017.

[4] Baidu Wenku, "Update ideas, creating features, comprehensively strengthen school physical education work," https:/wenku.baidu.com/view/1ca609e40975f46527d3e139.html, 2017-6-3. 
[5] SHI Hai-yan, "Present situation analysis and Countermeasures of sports field, equipment and facilities in rural primary schools," New Curriculum Research, vol. 6, no. 7, pp. 79-82, 2009.

[6] SHI Wen-qing, "Professional development path of PE teachers in primary and middle schools of Anshan city and influencing factors," Journal of University of Science and Technology Liaoning, vol. 36, no. 1, pp. 105-108, 2013. 